\title{
Lake Water Quality and Surrounding Vegetation in Dry Churiya Hills, Far-Western Nepal
}

\author{
Pawan K. Neupane' ${ }^{1}$ Madhukar Khadka' ${ }^{1}$ Radium Adhikari ${ }^{1}$ and Dinesh R. Bhuju ${ }^{2}$ \\ ${ }^{1}$ Central Department of Environmental Science, Tribhuvan University, Kirtipur, Kathmandu \\ ${ }^{2}$ Nepal Academy of Science and Technology, Khumaltar, Lalitpur \\ e-mail:dineshbhuju@gmail.com
}

\begin{abstract}
Mudka, Bedkot and Jhilmila are natural lakes in dry sub-tropic Churiya hills of Kanchanpur in far-western Nepal. A study was carried out on these lakes to prepare baseline information on water quality, floristic and structural features of adjoining forest vegetation, socio-cultural importance and threats to help support their sustainable use. The study was conducted in March (pre-monsoon) and November 2008 (post-monsoon). A significant seasonal variation $(\mathrm{p} \leq 0.05)$ in the physico-chemical properties of the lake waters was recorded. Adjoining forests of Mudka contained 23 species at canopy, 13 species at shrub and 27 species at herb strata, while that of Bedkot had 31 species of plants at canopy, 9 species at shrub and 37 species at herb strata, and Jhilmila had 23 species at canopy, no species at shrub and 47 species at herb strata. The most frequently seen trees were Mallotus philippensis and Shorea robusta in the forests surrounding Mudka and Bedkot whereas Jhilmila's surrounding forests contained $S$. robusta, Semicarpus anacardium, Syzygium cumini and Anogeisus latifolius. At shrub stratum, in the forest surrounding Mudka, M. philippensis had the highest density (633.3 no./ha) whereas in case of Bedkot, Solanum erianthum had the highest density (144.0no./ha). At herb stratum, the species with highest coverage at the respective forest were Ageratum conyzoides (7.14\%), Viburnum contifolium (8.5\%) and Themeda triandra (16.09\%). All three lakes possessed cultural values as the people visited the sites as pilgrimage and observed religious festivals mostly on full moon. However, unsustainable consumption of the resources from the surrounding forests is adding pressure on the condition of the lakes. Further, the area and depth of the lakes are diminishing due to the massive amount of sediments from fragile Churiya hills. This calls for the urgent conservation and good management of the lakes.
\end{abstract}

Key words: conservation, forest characteristics, seasonal variation, socio culture

\section{Introduction}

Lakes are distinctly noticeable physical feature as the body of water on the surface of Earth. They abound mostly in glaciated regions of northern hemisphere. The Himalayan range also contains a good number of lakes Bhuju et al. (2009) identified a total of 5,358 lakes on topo-sheets prepared in 1990s which are mostly glacial and tectonic lakes in the mountains or oxbow lakes in the lowlands. Lakes have multitude values. They moderate temperature and climate of the surrounding area and help maintain biodiversity. For humans, lakes are valuable as the source of freshwater and sites for recreational activities, while several of them hold religious values (Bhandari 1994).

The natural water bodies in dry hills of deep water table are rare and insignificant for their role in maintaining biodiversity of their surroundings. Churiya hills, also known as Siwalik, form a southernmost mountain belt in the Himalaya and present typical dry hills with poor water table consisting unconsolidated 
fluviatile sediments. At few places, these hills contain natural fresh water bodies (Bhuju 2006). Beside their role in regulating natural ecosystem and supporting wildlife visitors and migrating birds, their maintenance in such fragile arid landscape poses a scientific enquiry by itself. However, there is dearth of information and baseline data on these lakes that would support conservation management.

In Nepal, most of the scientific endeavors have been concentrated on the wetlands of international importance such as Ramsar sites. Thus, many of the wetlands are being ignored, which make them more vulnerable to degradation and disturbances. It is feared that several of them may get dried up before documented and such situation is more acute in the backwaters such as in Churiya hills (Bhuju 2004). This study intended to produce inventory on the terrestrial vegetation, physic-chemical characteristics of water and socio-cultural importance of wetlands at Churiya hills of Kanchnapur, viz. Mudka Tal, Bedkot Tal and Jhilamila Tal.

\section{Study Area}

Churiya hills are the first mountain range in front of Tarai plain in Nepal. They rise up to $1,800 \mathrm{~m}$ above sea level and contain unconsolidated highly erodible fluviatile sediments. The topography is rugged with numerous gullies and mound of talus and scree. On surface mostly Shorea robusta grows. It is pitch dry in the summer and even except the fault zone there is no trace of moisture in the non vegetated area. It is composed of sandstone in alternating layers and contains pebble horizon on the top part (Sharma 1990). Mudka Tal (2858’23’ N; $80^{\circ} 25^{\prime} 08.3^{\prime \prime} \mathrm{E}$, alt. 305m, area 2.0ha and max. depth 2m), Bedkot Tal (2901'36' N; 80¹9'14E, alt. 482m, area 5ha and max. depth $11 \mathrm{~m}$ ) and Jhilmila Tal (2904'02"N; 80¹1'28"E, alt. 985m area 8.5ha and max. depth $11 \mathrm{~m}$ ) lies in Jhalari village, Daiji village and Bhim Datta municipaltiy of Kanchapur district respectively (Table 1, Fig. 1).

Table 1. Lakes in the Churiya hills of Kanchanpur district selected for the study

\begin{tabular}{l|l|c|c|c|l|l|c}
\hline S N & Lake & $\begin{array}{c}\text { Altitude } \\
\text { (m) }\end{array}$ & $\begin{array}{c}\text { Area } \\
\text { (ha) }\end{array}$ & $\begin{array}{l}\text { Max. } \\
\text { Depth } \\
(\mathbf{m})\end{array}$ & Location & $\begin{array}{l}\text { Distance from } \\
\text { settlement (km) }\end{array}$ & Forest Type \\
\hline 1 & Mudka & 305 & 2 & 2 & Jhalari VDC & 4 & Mallotus-Shorea \\
2 & Bedkot & 482 & 5 & 11 & Daiji VDC & 7 & $\begin{array}{c}\text { Mallotus-Shorea } \\
\text { Shorea-Semicarpous }\end{array}$ \\
\hline
\end{tabular}

VDC $=$ Village Development Committee

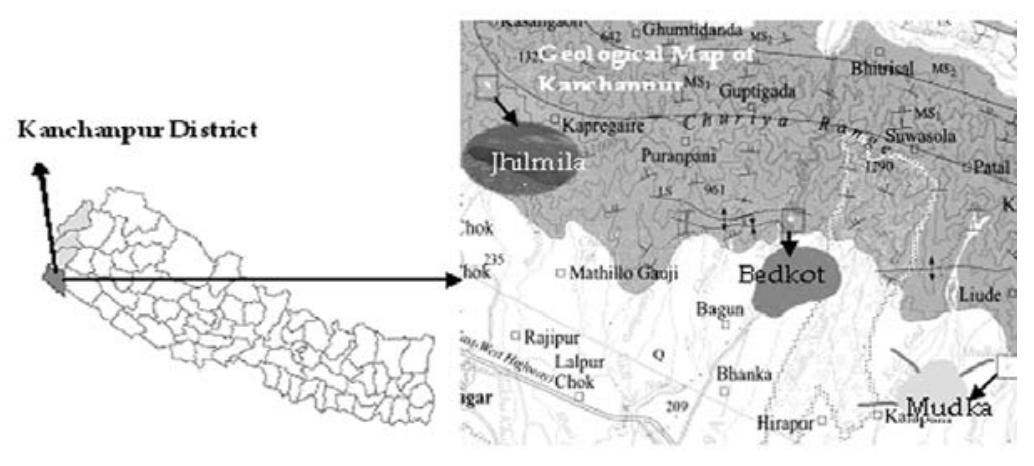

Fig1. Locations of study lakes in Nepal

\section{Methodology}

Physico-chemical analysis of water was conducted to determine the water quality of the lakes. A total of 5 , 10 and 15 water sampling sites, including inlet and outlet where present, were taken for Mudka, Bedkot and Jhilmila respectively. Analyses of the physicochemical parameters were done by following APHA (1998). 
For the analysis of terrestrial vegetation surrounding the lakes, random stratified sampling method was followed using a random table (Rohlf \& Sokal 1969). Three different quadrate size was determined for different strata; large (20mX20m) for canopy, medium ( $5 \mathrm{mX} 5 \mathrm{~m})$ for shrub and small ( $1 \mathrm{mX} 1 \mathrm{~m})$ for herb. Two medium and five small quadrates were laid inside the larger one. Various quantitative parameters (density, basal area, relative basal area, frequency \& coverage) were calculated following Kent and Coker (1992).

Socio cultural importance, utilization of the resources, threats, and conservation and management status of the lakes were studied by questionnaires method. Different open ended questions were asked to at least 50 respondents including local residents, leaders, government officers, shopkeepers, teachers, students, priest and visitors.

\section{Results and Discussion Water quality analysis}

There was significant ( $p \quad 0.05$ ) seasonal variation of water temperature in all the three studied lakes. In all, water temperature was higher during pre-monsoon than in the post-monsoon. In pre-monsoon average water temperature was $26.68 \pm 0.86^{\circ} \mathrm{C}, 26.43 \pm 0.46^{\circ} \mathrm{C}$ and $18.2 \pm 0.15^{\circ} \mathrm{C}$ in Mudka, Bedkot and Jhilmila respectively. The temperature in post-monsoon was lowered to $19.04 \pm 0.90^{\circ} \mathrm{C}, 20.88 \pm 0.32^{\circ} \mathrm{C}$ and $23.80 \pm$ $0.38^{\circ} \mathrm{C}$ respectively in them (Table 2). Natural bodies of water may exhibit seasonal and diurnal variations, as well as vertical stratification in temperature, which is related with the change in atmospheric temperature (Kundanagar et al. 1996).

The seasonal variation of water conductivity was also significant $(\mathrm{p} \leq 0.05)$ in the lakes. The average conductivity was $331.05 \pm 8.25$ ìsimen/cm, $233.82 \pm$ 9.71 ìsimen/cm and $177 \pm 13.38$ ìsimen/cm during premonsoon in Mudka, Bedkot and Jhilmila respectively, which increased to $515.49 \pm 7.41$ ìsimen/cm, $287.76 \pm$ 19.97 ìsimen/cm and $327.8 \pm 7.37$ ìsimen/cm respectively in post-monsoon. Similarly, the lakes showed significant seasonal variation of DO in preand post-monsoon. In pre-monsoon average DO was $6.15 \pm 0.20 \mathrm{mg} / \mathrm{l}, 5.00 \pm 0.15 \mathrm{mg} / \mathrm{l}$ and $6.80 \pm 0.23 \mathrm{mg} / \mathrm{l}$ in Mudka, Bedkot and Jhilmila respectively, while it was $6.81 \pm 0.71 \mathrm{mg} / \mathrm{L}, 5.76 \pm 0.22 \mathrm{mg} / \mathrm{L}$ and $4.62 \pm 0.20 \mathrm{mg} / \mathrm{l}$ respectively in the post-monsoon. Low DO in the summer could be the function of higher water temperature and decomposition of organic matter (Badge \& Verma 1985).

The average phosphate content was $0.15 \pm 0.11 \mathrm{mg} / \mathrm{l}$, $0.11 \pm 0.01 \mathrm{mg} / \mathrm{l}$ and $0.16 \pm 0.01 \mathrm{mg} / \mathrm{l}$ during premonsoon in Mudka, Bedkot and Jhilmila respectively. During post-monsoon it was $0.24 \pm 0.16 \mathrm{mg} / \mathrm{l}, 7.80 \pm$ $0.58 \mathrm{mg} / \mathrm{l}$ and $0.15 \pm 0.01 \mathrm{mg} / \mathrm{l}$ respectively. The seasonal variation of orthophosphate of the lakes might be due to the fluctuation on surface runoff, weathering of rocks, soil decay and mineralization of plants and animals remains (Kennan \& Job 1980). However, the seasonal variation of phosphate content was significant $(\mathrm{p} \leq 0.05)$ only in Bedkot.

The average total hardness was $233.23 \pm 33.89 \mathrm{mg} / \mathrm{l}, 446.76$ $\pm 13.70 \mathrm{mg} / \mathrm{l}$ and $42.15 \pm 2.33 \mathrm{mg} / \mathrm{l}$ during pre-monsoon at Mudka, Bedkot and Jhilmila respectively. During postmonsoon it was $298.12 \pm 46.44 \mathrm{mg} / \mathrm{l}, 271.05 \pm 28.63 \mathrm{mg} / \mathrm{l}$ and $125.50 \pm 7.60 \mathrm{mg} / \mathrm{l}$ respectively. Hardness indicates the presence of dissolved ions, mainly of calcium $\left(\mathrm{Ca}^{2+}\right)$ and magnesium $\left(\mathrm{Mg}^{2+}\right)$ which are acquired through the contact with rocks and sediments in the environment. In case of Mudka and Bedkot, there was presence of inlet, hence, the ions related to hardness were continuously added in all the seasons. In Jhilmila, there was absence of such inlet, so the ions were added in the lakes only during the monsoon season and accumulated till the postmonsoon. The seasonal variation of total hardness was significant $(\mathrm{p} \leq 0.05)$ in Bedkot.

Arsenic content was found to be nil at all the lakes during the study period.

\section{Forest structure and floristic composition}

Terrestrial vegetation has played a vital role in maintaining the lakes, Mudka, Bedkot and Jhilmila by acting as natural check dams for controlling the sedimentation from the fragile Churiya hills. These vegetation are also helping in mass stabilization. In case of mass stability, the protective benefit of woody vegetation range from mechanical reinforcement and restraint by roots and stems to modification of slope hydrology as a result of soil moisture extraction (Gray \& Sotir 1996). However, the vegetation present around the lakes were not that of 'restricted to wetlands' type, rather they were of terrestrial habit. 


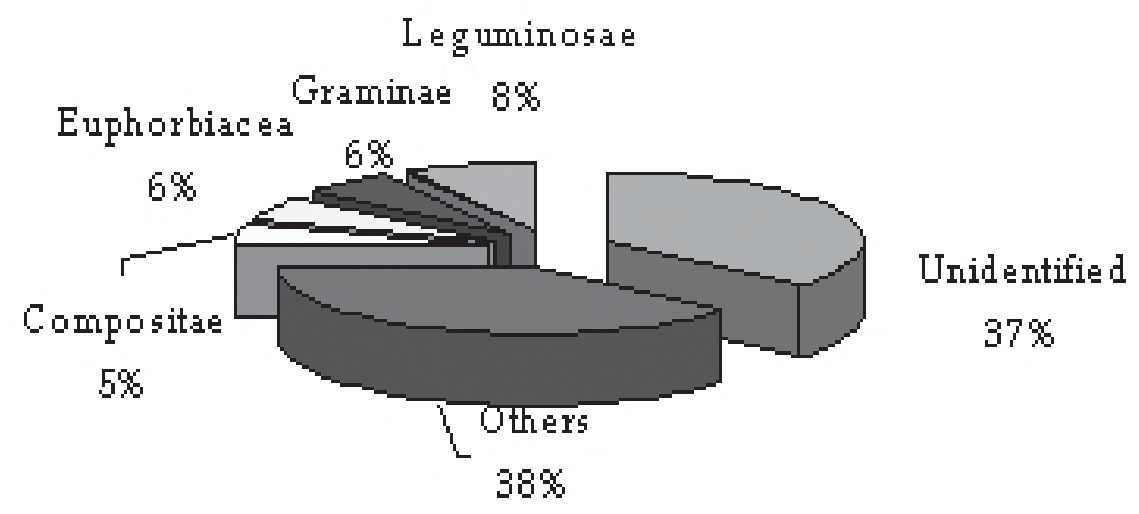

Fig 2. Distribution of plant species by families

presents floristic composition of the studied lakes. Altogether 120 plant species belonging to 29 families, 61 plant species belonging to 27 families and 42 plant species belonging to 27 families and 61 species belonging to 30 families were found at the forest surrounding Mudka, Bedkot and Jhilmila respectively. At the forest surrounding of Mudka and Bedkot, family Leguminosae had the highest number of plant species (17\% \& 12\% respectively) followed by Euphorbiaceae (10\% \& 7\% respectively) and Compositae (7\% \& 10\% respectively) whereas in the forest surrounding Jhilmila, Graminae had the highest number of plant species (8\%) followed by Leguminosae (7\%) and Euphorbiaceae (3\%).

By habit, the adjacent forest of Mudka was composed of $51.2 \%$ trees, $7.3 \%$ shrubs, $36.6 \%$ herbs and $2.4 \%$ climbers and ferns. In case of Bedkot, adjacent forest had $42 \%$ trees, $8 \%$ trees/shrubs, $7 \%$ shrubs, $3.8 \%$ herbs and 5\% climbers. At the forest surrounding the Jhilmila, 39\% trees and 61\% herbs were present.

Of the structural parameters of Churiya forests around three lakes, forests around Jhilmila showed a greater control of topography (average slope $35^{\circ}$ ), with little number of stem density and low basal area and tree diameter (Table 3). The major tree species comprised of Shorea robusta (Sal), Mallotus philipensis (Sindure), Adina cordifolia, Terminalia alata, Syzygium cumini, Largerstroemia parviflora and Schleichera oleosa (Table 4). The species are also the characteristics of lowland Tarai, which extend to the Chruiya hills in Nepal, some of them even cross the zone and reach mid-hills. This signifies the importance of Churiya as a key landscape conjoining lowland and Mid-hill belts in Nepal Himalaya.

At canopy stratum, 31 species in Bedkot and 23 species each in Mudka and Jhilmila were recorded. The most frequently seen trees at the forest surrounding Mudka were M. philippensis, S. robusta, Anogeissus latifolia, Trewia nudiflora and S. cumini. The basal area of the tree stratum was $39.5 \mathrm{~m}^{2} /$ ha with density 569.8no./ha, where $M$. philippensis had the highest density (220.8 no./ha) followed by S. robusta (94.8 no./ha). The highest relative basal area was $24.6 \%$ (M. philippensis). The most frequently observed trees around Bedkot Tal were $M$. philippensis and

Table 3. Structural parameters at tree stratum of Churiya forest around the three lakes in Far-western Nepal

\begin{tabular}{l|c|c|c|c|c}
\hline \multirow{2}{*}{ Lakes } & Basal Area (m²/ Ha) & \multicolumn{2}{|c|}{ Density (no./ ha) } & Mean DBH (cm) & $\begin{array}{c}\text { Ground Vegetation } \\
\text { Coverage (\%) }\end{array}$ \\
\cline { 2 - 4 } & & Live & Dead & & \\
\hline Mudka Tal & 39.50 & 569.8 & 36.50 & 20.50 & 55.0 \\
Bedkot Tal & 28.90 & 424 & 4.20 & 19.56 & 31.8 \\
Jhilmila Tal & 24.91 & 476 & 4.20 & 16.04 & 17.0 \\
\hline
\end{tabular}


Pawan K. Neupane et al./Lakes Water Quality

Table 4. Relative basal area (\%) of major tree species around three lakes in far-western, Nepal

\begin{tabular}{l|l|l|l}
\hline Name of Species & Mudka Tal & Bedkot Tal & Jhilmila Tal \\
\hline Mallotus philippensis & 24.60 & 5.89 & 1.36 \\
Shorea robusta & 21.90 & 49.94 & 46.90 \\
Adina cordifolia & 15.8 & 0.01 & 0.17 \\
Lagerstroemia parviflora & 7.30 & 0.12 & 0.00 \\
Pterocarpus marsupium & 6.80 & 0.00 & 0.00 \\
Schleichera oleosa & 6.80 & 8.63 & 0.00 \\
Syzygium cumini & 6.30 & 0.01 & 14.11 \\
Terminalia alata & 0.10 & 15.14 & 16.99 \\
Kaeen & 0.00 & 8.03 & 0.00 \\
Pinus roxburghii & 0.00 & 0.00 & 6.67 \\
\hline
\end{tabular}

and $S$. robusta the basal area of was $28.95 \mathrm{~m}^{2} /$ ha with density 424.0no./ha with $M$. philippensis having the highest density (149.0no./ha) followed by $S$. robusta (96.0no./ha). The highest relative basal area was 49.94\% (S. robusta). The most frequently seen trees surrounding Jhilmila were S. robusta, S. anacardium, S. cumini and A. latifolius. The basal area of the tree stratum was $24.9 \mathrm{~m}^{2} /$ ha with density 475.0 no./ha. $S$. robusta had the highest density (185.87no./ha) followed by $M$. phillippensis (41.22no./ha). The highest relative basal area was $46.9 \%$ (S. robusta).

The invariably occurrence of similar species showed the similarities of the lake habitats. As Jhilmila is located at relatively higher altitude, it contained Pinus roxburghii as well. Bhuju (2006) recorded greater degradation of Churiya forest with higher number of stem density and low basal area. There was inverse J shape diameter class distribution of $M$. phillippensis at the adjoining forests of Mudka, while the S. robusta had the class distribution with clefts at places. This indicates the degradation of Sal timber forests and replacement by less important wood Sindure. Comparatively, Jhilmila had forest condition with inverse J shaped DBH class of $S$. robusta, and less number of $M$. phillippensis.

At shrub stratum 13 species were recorded at the forest surrounding Mudka, whereas at the forest surrounding Bedkot, nine species were recorded. In case of Jhilmila, no shrubs species was recorded. In the forests of
Mudka, M. philippensis had the highest density (633.3 no./ha) followed by S. robusta (166.7 no./ha). In case of Bedkot, Solanum erianthum had the highest density (144.0no./ha) followed by Clerodendron viscosum (44.0 no./ha).

At herb stratum, 27 species, 37 species and 47 species were recorded in the forests surrounding Mudka, Bedkot and Jhilmila respectively. The most frequently occurring species were in Mudka forest were Viburnum contifolium (freq. 79.2\%), Argemone mexicana (freq. 79.2\%) and Ageratum conyzoides (freq. 58.3\%). In Bedkot forest, the most frequently occurring species were: V. contifolium (freq. 68\%) and S. robusta (freq. $65.6 \%)$, and in Jhilmila, the most frequently occurring species were: Themeda triandra (freq. 21\%), A. conizoides (freq. 18\%), S. robusta (freq. 17\%), Enulacapa compositae (freq. 13\%) and V. contifolium (freq. 10\%).

The densities of dead and/or damaged tree species were found to be 36.5no./ha, 4.26no./ha and 4.26no./ ha in the forests surrounding the Mudka, Bedkot and Jhimila Tal respectively. The ground vegetation and litter coverage of these forests were $55 \%$ and $35.7 \%$, $31.86 \%$ and $16.8 \%, 17 \%$ and $47.17 \%$ respectively. The higher coverage of ground vegetation in Mudka forest could be attributed to its degraded forest with less number of trees. Among the three studied lakes, Mudka is located in the nearest to the human settlement, thus, more accessible for human activities. 
a. Mudka Tal
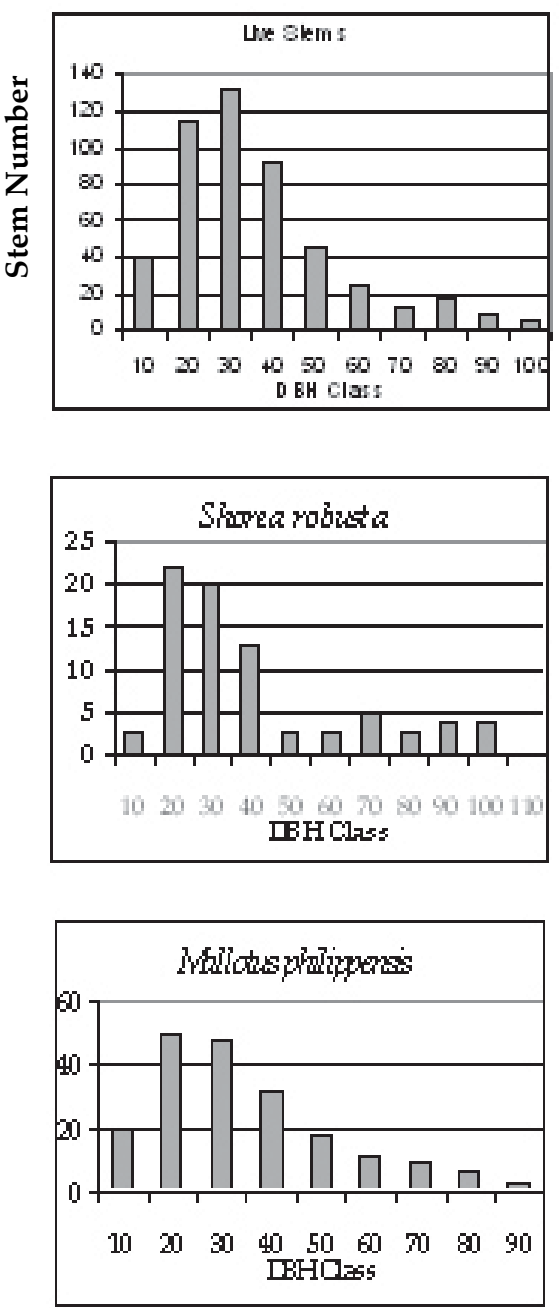

b. Bedkot Tal
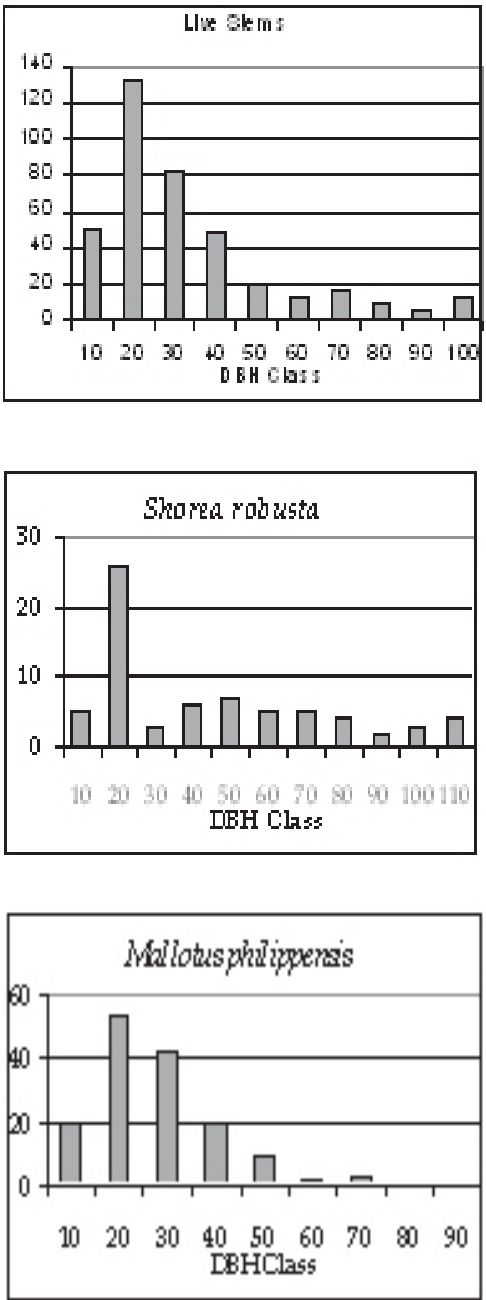

c. Jhilmila Tal
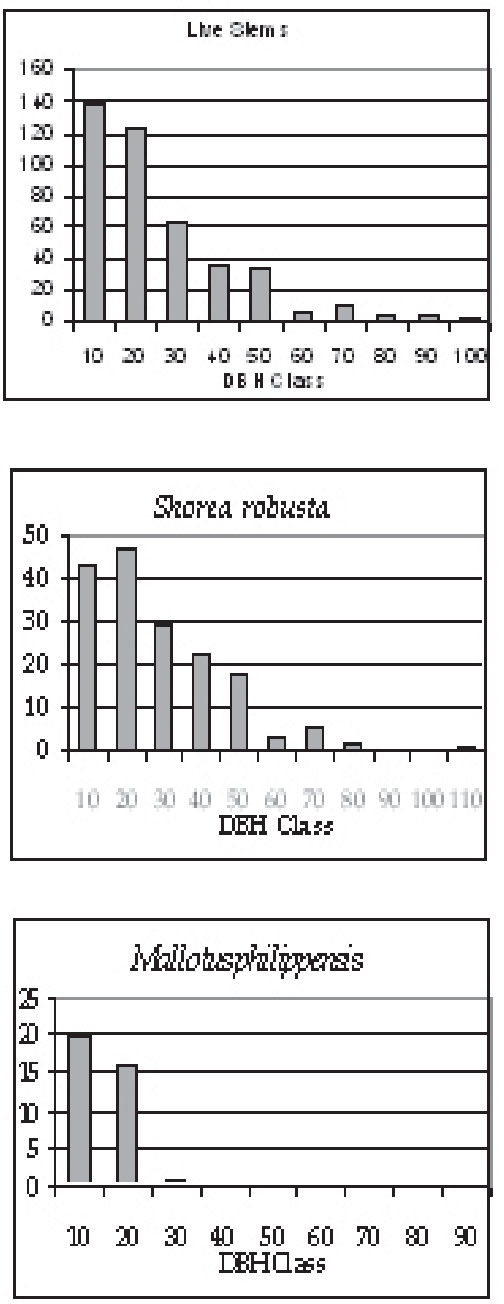

Fig. 3. Diameter class (in $\mathrm{cm}$ ) distribution of major tree species in adjoining forests of Mudka (a), Bedkot (b) and Jhilmila (c) lakes in Kanchanpur district, far-western Nepal.

\section{Sociocultural activities}

People living near the Mudka, Bedkot and Jhilmila have developed age-old socio-cultural relationship with the lakes forming a part of their life and livelihood. With the highly respected deities Baijanath and Siddhanath, these lakes are the sites of religious values. These lakes have played an important role in social integration as people from various parts visit the sites during special occasions. The cultural activities associated with the lakes were mainly Magh Shukla Dashami, Maghe Sakranti, Shiva Ratri, Bishu (local festival), and Dashai. During these festivals people from various places like Daiji, Jhalari, Suda, Dhangadi,
Kailali, Mahendranagar, and also from faraway districts like Dadheldhura, Baitadi, Darchula and India also visit these lakes. At Bedkot, the local religious Guru Dhami pays special visit to the lakeside and mumble invocations. The local people in Jhilmila believe that the color of the lake changes three times throughout a single day, that's how the name was coined. Such socio-cultural activities in the lake area by the visitors' have, though not intended sometimes negative influence as well. People offer Abir (red powder) containing hazardous chemicals, which directly pollute the water. Similarly, the polythene wrappers of Dhup and other goods are scattered indiscriminately. 


\section{Conservation and management}

Local people and authorities have shown concern on the conservation of the lakes. There are already committees formed to conserve and manage Bedkot and Jhilmial since over two decades. However, such committees have yet to be established for Mudka. Stone wall has been constructed in Bedkot, which is helpful to protect the lake from encroachments. Similarly, foot trails have been constructed to reach Mudka and Jhilmila for the visitors' convenience. Bedkot is made accessible by road from Daiji to Jogbuda.

\section{Threats to the wetland}

These lakes are facing threats from various anthropogenic activities in recent days. Flash flood during rainy season entering the lakes with huge amount of silt is another major threat to all the three lakes. The road construction from Daiji to Jogbuda is also not in favor of the lake water in Bedkot as it crosses the upper catchment of the lake creating sedimentation problems. Unsustainable levels of grazing have also resulted in degradation of the lakes. There is a high dependence on forest surrounding the wetlands like extracting forage and fodder, firewood, timber and medicinal herbs as well. Such dependency on lakesite resources has depleted the condition of the lakes. The human activities such as deforestation in the surrounding forests have increased the erosion problems and silt flow. This has direct and negative impact on the quality of the lake waters. Poaching and illegal hunting of small mammals, fish and birds is another threat to the biodiversity of the lake-area.

Cultural and religious activities such as Pooja using contaminated Abir during specific festivals have been a major source of metallic pollution of lakes. Water pollution and indiscriminate waste disposal by the pilgrimage is also degrading the quality of the lake environment. The fragile ecology of the churiya hills and the lakes standing on such area may be affected by even minor changes in the hydrological regime or micro-climate. Little attention, however, has been given to the processes that govern their formation, growth, distribution and demise. If, for any reason, the nutrient and/or hydrological cycles greatly change, then this water and/or nutrients concentration will be changed, which will sure to affect the ecosystem of the whole lake.

\section{Acknowledgements}

We thank Ms Anju Thapa and Mr. D.P. Joshi for their help in water analysis and plant identification. Our special thanks go to all the local residents of the study sites for their valuable cooperation.

\section{References}

APHA. 1998. Standard method for the examination of water and waste water. $20^{\text {th }}$ edition. American Public Health Association, Washington D.C.

Badge, U.S. and A.K. Verma. 1985. Limnological studies on J.N.U. Lake. New Delhi, India. Bull. Bot. Soc. Sagar 32:16-23.

Bhandari, B. 1994. Institutions and capability in wetlands management in Nepal. In: Safeguarding wetlands in Nepal. Proceeding of the national workshop on wetlands management in Nepal (3-5 March 1993), Kathmandu (Eds. B. Bhandari, T.B. Shrestha \& J. McEachern ). IUCN-Nepal, Kathmandu. pp. 119-136.

Bhuju, D.R. 2004. Sukkha Bhumika Rasila Taalharu (in Nepali). Hakahaki 7(3):33-35.

Bhuju, D.R. 2006. Ecology of the Churiya in the Nepal Himalaya. Conservation Biology in Asia (Eds J.A. McNeely, T.M. McCarthy, A. Smith, L. OlsvigWhittaker and E.D. Wikramanayake). Society of Conservation Biology Asia Section and Resources Himalaya Foundation. Pp. 62-67.

Bhuju, U.R., M. Khadka, P.N. Neupane and R. Adhikari. 2009. Lakes of Nepal:5358-Map based inventory. report. National Lakes Conservation and Development Committee, Kathmandu, Nepal.

Gray, D.H. and R.B. Sotir. 1996. Biotechnical and soil bioengineering slope stabilization: A practical guide for erosion control. John Wiley and Sons, Chichester, USA.

Kennan, N. and S.V. Job. 1980. Diurnal depth-wise and seasonal change of physicochemical factors in Sathiar reservoir. Hydrobiologia 70:103-117.

Kent, M. and P. Coker. 1992. Vegetation description and analysis. John Wiley and Sons, Chichester, USA.

Kundangar, M.R.D., S.G. Sarwar and J. Hussain. 1996. Zooplankton population and nutrient dynamics of wetlands of Wular lake, Kasmir, India. In: Environment and biodiversity: In the context of South Asia (Eds P.K. Jha, G.P.S. Ghimire, S.B. Karmacharya, S.R. Baral \& P. Lacoul). Ecological Society (ECOS), Nepal. pp. 128-134.

Rohlf, R.F. and R.R. Sokal. 1969. Statistical tables. W.H. Freeman and Co. USA.

Sharma, C.K. 1990. Geology of Nepal Himalaya and adjacent countries. Printing Support Pvt.Ltd. Kathmandu, Nepal. 
Nepal Journal of Science and Technology 11 (2010) 181-188 